\title{
Essentials for health care providers traveling to low-resource countries
}

This article was published in the following Dove Press journal:

Nursing: Research and Reviews

27 September 2012

Number of times this article has been viewed

M Gail Hill

Karen McCarty

Deborah Bowers

School of Nursing, University of Alabama at Birmingham,

Birmingham, AL, USA
Correspondence: M Gail Hill

School of Nursing, University of Alabama

at Birmingham, Room 502, I70I

University Boulevard, Birmingham,

AL 35233, USA

Tel + I 2059346587

Fax +l 2059969165

Email hillg@uab.edu
Abstract: The purpose of this article is to provide recommendations regarding personal planning for short-term trips to low-resource areas with the purpose of providing health care. Recommendations are based on lessons learned by the three authors during almost 5 years of cumulative time spent in 15 different countries on three continents in international nursing experiences. Recommendations are organized according to essential needs and nice-to-have materials. Suggestions are further sorted by categories of medicines, clothing, entertainment, documentation, safety, personal hygiene, and miscellaneous. Consideration has been given to space and weight limitations, as well as to practical and potentially critical needs. Each recommendation comes from the lived experiences of one, two, or all three authors, and has been found to be worth sharing with those who would experience health care delivery under nonoptimal conditions.

Keywords: international nursing, travel essentials, low-resource countries

\section{Introduction}

The purpose of this article is to provide recommendations regarding materials to pack when preparing for short-term trips of up to one month for the purpose of improving health care in low-resource areas. Low-resource countries, for the purpose of this article, are defined as countries with a heavier-than-usual burden of disease, an insufficient number of health care professionals and health care facilities, and a distribution of those facilities that is insufficient to serve all the country's population.

Essential travel recommendations are based on lessons learned during almost 5 years of cumulative in-country time by the three authors. We have functioned in low-resource countries in many capacities: as faculty consultants for international schools of nursing, as nurses and nurse practitioners delivering care, as World Health Organization Collaborating Center scholars, as faculty in student study-abroad courses, ${ }^{1}$ and as organizers and leaders for faith-based medical missions. The countries/territories visited include Brazil, China, Colombia, Gaza, Guatemala, Honduras, India, Israel, Mexico, Peru, South Africa, South Sudan, Thailand, Venezuela, and Zambia.

In addition to on-site knowledge, we have benefited from knowing many others who give regularly of their time to improve health care around the world. The selfless giving of time and abilities by health care providers is impressive, as shown by a Google search in April, 2012, which produced 364,000 online websites for health-related trips around the globe. Just one of those Internet sites listed 10,732 medical mission opportunities by region. ${ }^{2}$ A search of Nursing.org using the search string "mission trip" listed 22 sites from which to obtain information about health care trips. ${ }^{3}$ 
Each recommendation made here comes from the lived experiences of one, two, or all three of us, and many lessons have been learned through difficult experiences. One of us experienced a government coup, and another had every form of money - cash and credit cards - refused, making food acquisition difficult. Two of us were retained at customs when trying to enter the target country, all have been ill without having the appropriate medications, and one person was summoned to the local police station to account for her actions. Another worked beside a nurse colleague who was so dehydrated, she remained hooked to an intravenous fluid infusion all day while providing care. Transportation strikes during which vehicles were stoned by local workers, and confiscation of medications at airport immigration have been part of our experiences. With the goal of preventing others from having unfortunate experiences, we offer the information that follows.

These suggestions are organized as essential needs and nice-to-have materials, categories based purely on the authors' opinions. Packing considerations have been given to space and weight limitations as well as to practical and potentially critical needs. We have carried these recommended items in one checked bag, one carry-on bag, and a purse, all within airline standard-weight limits. The essential-needs category is probably overstated; strictly speaking, one must only have nutrition, warmth, an adequate amount of sleep, and safety. But today's health care provider is accustomed to a level of comfort that need not be abandoned entirely.

\section{Essential needs}

Within this section, suggestions are sorted by headings of safety, medicines, documentation, money, personal hygiene, clothing, and miscellaneous. Arguments can be made that "essential" may not apply to all of these, but experience gained over 35 years has resulted in this list.

\section{Personal safety}

This category will be discussed first because all others become inconsequential if safety is seriously compromised. Some items may seem of very little importance in the face of international terrorism, kidnapping, assassinations, and wars. However, the list has served us well when facing dangers of considerably lesser weight than those just noted.

A small flashlight with extra batteries (sizes AA and AAA, especially) will allow safe passage to the bathroom at night and shoe checks for misguided scorpions. The batteries will also provide a means to resuscitate remote controls for air conditioners and televisions in local lodging, where these amenities may be found. Some travel stores have small flashlights that can be adjusted to serve as bedside lanterns. Candles and matches can be purchased in-country in the airport city prior to travel into remote areas.

If sunscreen and mosquito repellent (Deet 25\%) are packed in the carry-on bag, they must be purchased in sizes allowed by airport security; it helps no one except the mosquito to be required to relinquish the repellent at the airport. These lotions or sprays have to go onto the body in a particular order: sunscreen goes on first and is allowed to dry, then mosquito repellent follows.

Those who need prescription lenses absolutely should pack an extra pair of glasses, even if contact lenses are worn at home; an eye infection could imperil the whole trip. A bottle of artificial tears in the carry-on bag will provide comfort for dry eyes during the trip. Sunglasses are a must for both hot and cold climates.

A zippered pillowcase will allow comfortable sleep on pillows that look suspiciously as if they have been drooled on by multiple individuals. These pillowcases are available at most department stores, and can be used to pack dirty laundry for the trip back home.

A plastic jar of peanut butter will provide a source of both protein and fat for those times when carbohydrates (often rice) are the only foods available. Cheese crackers and granola bars provide a little variety. Only commercially packaged foods should be packed to avoid confiscation at airport immigration. When one of us was caught in a revolutionary coup and had to stay inside the room for a couple of days, the packed food came in very handy. All food should be placed in plastic bags in case of spillage inside the suitcase.

Safety alerts, warnings, or advisories for the destination country usually can be found on government websites. In the United States, for example, the best advisory information source is the US Department of State's Bureau of Consular Affairs. ${ }^{4}$ Each person should register with the home-country consulate prior to the trip and become familiar with customs, culture, import restrictions, and regulations for the destination.

As soon as possible, the addresses and phone numbers of the best hospital, emergency department, or clinic nearest to one's in-country work site should be obtained and secured in a small booklet of essential information to be placed in a purse or carry-on bag. It may be possible to have this information prior to departure from home if one is working with an organization based in the target country. 


\section{Medications}

All personal oral medications can be obtained from one's home-country pharmacist in plastic snack bags for easy packing. These must have official pharmaceutical labels; customs officials may confiscate medications without these labels. The same labeling recommendations apply to any nonpharmaceuticals such as herbal supplements. Medications should always be packed in a carry-on bag. Mixing different medications in the same container may arouse suspicion, and worse, result in confiscation. Confiscation of medication is a time-consuming hassle, and could result in an arrest should there be a suspicion of smuggling illegal substances.

One of us was summoned to a local police station when a relative shipped a package containing tiny eyeglassframe screws and a small magnifying glass. The charge was "importing medical equipment without a license." Fortunately, she was able to point to the large safety pin temporarily holding her eyeglasses together and subsequently was released from custody.

A few additional doses added to the amount of medications calculated to cover the trip length is a good idea. In case more doses are needed, a record of the generic names and prescription instructions will assist in purchases made while in-country. A more complicated but helpful idea is to have the target country's vernacular names of the medications. Many countries do not require a prescription to obtain medications from local pharmacies - often called apothecaries. Be aware of the possibility of fraudulent pharmaceuticals in any country.
There are countries where opioids can be obtained over the counter; availability does not mean the action is legal. While ease of purchase may tempt the individual with a cough to obtain codeine cough syrup on the black market, the possession of this medication might delay the traveler at customs on the trip home. Be aware of what can be legally carried back home.

The general medication suggestions that follow may not be suitable for everyone; personal physicians should be consulted prior to implementation of these ideas. Factors such as preexisting disease, immunocompetency problems, and interaction with current medications can restrict what is safe for any individual to take. See Table 1 for essential medications and vaccinations.

The flight is often a long one. We have used both diphenhydramine and prescription sleep aids to achieve useful rest during flight. Diphenhydramine is inexpensive, but carries its own potential problems: dehydrating effects combined with the immobility of long flights present a risk of deep vein thrombosis formation. The type of clots that result from immobility on long air flights are composed of fibrin, which is not affected by aspirin. ${ }^{5}$ Instead, hydration with water instead of sodas or alcohol, below-knee compression stockings, ${ }^{6}$ and walks in the aisle at regular intervals should sufficiently address the problem of deep vein thrombosis.

Scopolamine patches may be necessary for those prone to motion sickness. Travel on small, in-country planes, and cramped, local buses or cars over rough roads can cause even the hardiest of travelers to experience motion sickness.

Table I Essential medications to pack

\begin{tabular}{|c|c|}
\hline Medication & Rationale \\
\hline Diphenhydramine & Sleep on the plane and in noisy environments \\
\hline Scopolamine patches & Motion sickness \\
\hline Quinolone or metronidazole & Traveler's diarrhea; avoid alcohol with metronidazole \\
\hline Loperamide & If clear, watery stools are prolonged \\
\hline \multirow[t]{2}{*}{ Quinolone } & Urinary tract infection (women only) \\
\hline & Male UTIs are rare, so refer to a physician \\
\hline Prochlorperazine & Nausea and vomiting; overdose is possible \\
\hline Bismuth subsalicylate & To settle a sensitive stomach; not for children \\
\hline Acetaminophen or ibuprofen & Headaches or minor soreness \\
\hline Opioid pain medication & Serious pain control \\
\hline Epinephrine self-injection pen & Anaphylaxis; give intramuscularly in lateral thigh \\
\hline Hydrocortisone cream & Pruritis \\
\hline Triple-antibiotic cream & Small wounds (insect bites, scratches) \\
\hline Doxycycline or atovaquone/proguanil or chloroquine & $\begin{array}{l}\text { Malaria prophylaxis; choice is based on expense, ease of dosing, pregnancy category, } \\
\text { local resistance, and side effects }\end{array}$ \\
\hline Personal medications & May not find a specific medication in-country; take enough to cover time plus a few more days \\
\hline Preexposure rabies vaccination & $\begin{array}{l}\text { Will provide more time to get to definitive care; three intramuscular injections over } \\
28 \text { days - start early }\end{array}$ \\
\hline
\end{tabular}


These patches must be applied in advance to be effective, and require a prescription in some countries.

Once in-country, there is often the risk of travelers' diarrhea. High-risk destinations are countries in Asia, Africa, and Latin America. ${ }^{7}$ Ideally, laboratory work would be done to determine the exact cause, but this service is often unavailable. The most common cause is enterotoxigenic Escherichia coli bacteria, which attach to the lining of the intestine and release a toxin resulting in diarrhea and abdominal cramps. However, diarrhea can be caused by less common bacteria, viruses (rare), or parasites.

Travelers' diarrhea is most commonly acquired through contaminated drinking water or food. ${ }^{7}$ Cautionary actions include ingesting only bottled, boiled, or treated water; ingesting no shower water; and using bottled water for dental hygiene. The use of personal utensils, purchased in-country, to peel fruit avoids the risk of kitchen knives contaminated through preparation of other foodstuffs. Avoid juices, since these may have been reconstituted with local water. Uncooked food, such as salads and unpeeled fruit - especially raspberries, strawberries, and grapes - are never considered safe for travelers, nor are open buffets and street-vendor food, no matter how tantalizing and clean they may appear. Dairy products and undercooked or raw meat and fish also pose risks.

Safe foods and liquids to consume include soft drinks and bottled water, any food that has been boiled or fried, and commercially packaged foods. Water-purification tablets can be purchased and added to local water. While we have often consumed a boring diet consisting of a limited variety of foods, good health has been the reward.

Antibiotics used as prophylaxis for travelers' diarrhea can backfire, since the medication itself can produce diarrhea. The three of us treat diarrhea with quinolone one tablet twice a day for 3 days, or with metronidazole $500 \mathrm{mg}$ three times a day for 5 days. The quinolone can double for treatment of acute uncomplicated urinary tract infection in women $(250 \mathrm{mg}$ every 12 hours for 3 days). ${ }^{8}$ Mild diarrhea may not require medication, since travelers' diarrhea is usually self-limiting. Individuals taking an acid blocker for gastroesophageal reflux disease are more susceptible to travelers' diarrhea than others because stomach acid kills some ingested bacteria.

If travelers' diarrhea is accompanied by nausea and/or vomiting, prochlorperazine, available in either tablet or suppository form, makes a good addition to any medicine kit. In tablet form, the adult dosage is three to four times daily; suppositories can be taken twice a day. No increase should be made to these doses, since overdose is possible.
If vomiting persists, with the resultant risk of dehydration, it is sometimes possible to buy injectable medications from a local pharmacist. The important thing to avoid is dehydration; it is a very serious condition. ${ }^{9}$

Loperamide is recommended if clear, watery stools continue. Bismuth subsalicylate tablets help to settle a sensitive stomach. Bismuth subsalicylate should never be shared with children because it contains aspirin (Reye's syndrome potential). There are significant side effects to any medication, so attention to developing problems is essential.

Pediatric electrolyte strips, obtained over the counter in most local pharmacies, provide an option for replacing sodium and potassium lost through vomiting and diarrhea. In addition, oral rehydration fluid using $1 / 2$ teaspoon of salt and 6 teaspoons of sugar mixed in $1 \mathrm{~L}$ of safe drinking water works very well. It is not a good idea to pack premixed dry ingredients in luggage because suspicious-looking bags of white substances can get the traveler in unnecessary trouble. Instead, take commercial packets of sugar and salt. A very detailed recipe for rehydration fluid is found at the World Health Organization website. ${ }^{9}$

Analgesics such as acetaminophen and ibuprofen are good for minor nuisances, such as headaches or muscle soreness. A stronger pain medication will be welcomed should a malady such as a broken bone or toothache occur while hours away from health care. Your physician may be willing to prescribe a few opioid pain tablets for just such emergencies; it is best to pack any regulated medication in small amounts, and in officially labeled containers to avoid problems in customs. Many pain medications are dispensed in combinations with other medications. Forgetting this can result in severe consequences such as acetaminophen overdose.

Even without any history of an allergic reaction, a first reaction abroad could be severe. We strongly recommend carrying an epinephrine self-injection pen in case a critical allergic reaction develops. The epinephrine should never be injected intravenously, just intramuscularly into the lateral thigh - never into the buttock. ${ }^{10}$ Topical applications such as anti-itch hydrocortisone and triple-antibiotic therapy may be useful for local allergic reactions.

Band-Aids of various sizes are absolutely essential for foot blisters and multiple other uses. Distributing these individually inside packed shoes will save luggage space.

International certificates of vaccination must include vaccinations required for entry into the target country as well as for stopover countries en route. Specific vaccination information can be obtained at academic medical centers that have a geographic medicine department. The US Centers for Disease 
Control and Prevention's website provides useful vaccination information for those who must order medications through a local apothecary or health department. ${ }^{11}$ Some vaccinations involve a series of injections, so this planning must start 4-6 months prior to departure.

Short-term health care providers often will work in areas many miles from a supply of rabies vaccine. Preexposure rabies vaccination, while expensive, is an excellent idea in these cases. "Pre-exposure rabies vaccination consists of three full intramuscular (deltoid only for adults) doses of cell-culture- or embryonated-egg-based vaccine given on days 0,7 , and 21 or 28 (a few days' variation in the timing is not important)." ${ }^{\prime 2}$ This does not replace post-bite treatment of two booster doses of vaccine but provides more time to reach a medical facility equipped to render care. For more details see, the World Health Organization's website page on international travel and health/rabies. ${ }^{12}$

Malaria prophylaxis is essential for most tropical countries. ${ }^{13}$ There are several options, some much more expensive than others. (1) Doxycycline is inexpensive, but carries with it a sun-sensitivity warning; it should never be taken during pregnancy. (2) Atovaquone/proguanil is expensive, but a good choice for last-minute travelers since it can be started 1-2 days before traveling. This medication is preferred and well-tolerated, but cannot be taken in pregnancy. (3) Chloroquine is taken weekly, and can be used in all trimesters of pregnancy. Its use is limited by some preexisting health problems. Chloroquine must be started 1-2 weeks prior to travel and continued for 4 weeks afterwards. There are some areas where resistance to this medication has developed..$^{9}$ Other medications for malaria prophylaxis are available. The target country may have recommendations or requirements regarding choices.

\section{Documentation}

A photocopy of the passport face page, left with a friend or family member at home, and several copies of the face page distributed among luggage pieces provides valuable information should the passport be lost. See Table 2 for important documentation to have. Two of us have been asked to produce extra passport-sized photographs and copies of a curriculum vitae or résumé for documentation at customs. Carrying the passport at all times while traveling to and within the target country is strongly recommended. A photograph of luggage, packed in the carry-on bag, will assist in identification of lost luggage.

Some countries require that the passport not expire within 6 months of the date for leaving. They do not always
Table 2 Essential papers to take on the trip

\begin{tabular}{|c|c|}
\hline Papers & Rationale \\
\hline Passport & $\begin{array}{l}\text { For travel across borders, } \\
\text { identification }\end{array}$ \\
\hline Photocopy of passport & $\begin{array}{l}\text { Leave with family at home in case } \\
\text { of passport loss }\end{array}$ \\
\hline Copies of face page of passport & $\begin{array}{l}\text { With the traveler for replacement } \\
\text { of lost passport }\end{array}$ \\
\hline Extra passport-size photographs & Sometimes required at customs \\
\hline Curriculum vitae or résumé & Sometimes required at customs \\
\hline List of purchases & For home-country customs \\
\hline International driver's license & $\begin{array}{l}\text { In case a car rental is needed - } \\
\text { optional }\end{array}$ \\
\hline Professional credentials & If planning to function in the role \\
\hline $\begin{array}{l}\text { Local license or permission to } \\
\text { practice (letter) }\end{array}$ & $\begin{array}{l}\text { Obtained from target-country } \\
\text { health ministry prior to trip }\end{array}$ \\
\hline Cash, credit card, ATM card & $\begin{array}{l}\text { Several forms of money in case } \\
\text { one form is not accepted }\end{array}$ \\
\hline Contact information & $\begin{array}{l}\text { Family or friends may need to be } \\
\text { notified; put this in a place easily } \\
\text { found by others }\end{array}$ \\
\hline $\begin{array}{l}\text { Credit card and bank contact } \\
\text { information }\end{array}$ & $\begin{array}{l}\text { In case prior notification of travel } \\
\text { is not honored }\end{array}$ \\
\hline
\end{tabular}

enforce the policy upon entering the country; the problems can arise at the end of the visit. For this reason, travelers are strongly urged to renew the passport if there are only 6 months remaining before expiration, even if the trip abroad is only for 2 weeks. Additionally, at least three blank pages are necessary in the passport when traveling internationally; the last pages are for amendments and endorsements, and may not be accepted for use as visa pages. Some countries require the traveler to produce a letter of invitation from the health ministry or other organization.

Prior to arrival in the target country, travelers will be asked to declare their status: visitor, student, businessperson, or other. When possible, the appropriate category should be determined prior to departure from home. Some countries require an expensive payment at immigration when the business category is selected. However, should visitor status be selected in order to avoid the expense and the truth then discovered, entry into the country may be refused. In our experience, health care volunteers are considered to be in the business category. Visitor status places limitations on the amount of time that can be spent in-country, and may not allow multiple entries.

It is always best to be honest. It is especially egregious to enter a country for the purpose of sharing a religious faith and lying about this at immigration. This last behavior, should the truth be discovered, endangers the long-term religious workers who have legal status in the country. A tactful, predetermined, and honest answer, such as, "Our church 
has sent us to provide assistance to the earthquake victims" will be the best option.

A small blank booklet will come in very handy for several reasons: (1) a list of local phone numbers for calling taxis; a reliable taxi driver (arrives on time, drives safely, and doesn't price-gouge) is invaluable; (2) the phone number for in-country sponsors; (3) addresses of local health clinics and emergency rooms; (4) the phone number of your country's embassy; contact numbers posted on websites are often for use only from your home country; (5) your desktop computer's remote access information, just in case; Internet cafés often can be found in even the smallest of towns; the cost is very low, but the speed is usually slow; and (6) on the return flight, a card will be distributed on which each traveler must list purchases made while outside the home country. This list for customs is difficult to reproduce from memory, so an item and price list maintained throughout the trip will be helpful.

If the traveler will be reimbursed for the trip, we recommend taking a second small booklet and clear tape. Each receipt affixed in the book with needed notes will keep expenditures in chronological order and provide proof of purchases.

International driver's licenses are recognized in 175 countries and will be needed if a rental car becomes necessary. ${ }^{14}$ Governments everywhere are becoming more sophisticated in overseeing the safety of their citizens; the authors have never been asked to produce professional credentials, but recommend packing them. If a local license or permission to practise is required, this can usually be obtained through the health ministry prior to traveling.

\section{Money}

Our recommendation is to take several forms of money: cash, a credit card, and an ATM card. On arrival, it is wise to exchange a small amount of money at the airport for immediate transportation and snacks. However, a better rate can often be obtained later at local banks or even the supermarket if you exchange currency.

\section{Cash}

Crisp, completely unmarked, and brand-new, moderatedenomination bills - US $\$ 100$ bills, for example - of the very latest date are usually required for exchange. One of us took older, used bills, and found that no one, not even banks, would exchange these. When obtaining local currency, it is better to refuse to accept old local bills; some countries issue new currency from time to time, and retailers will refuse to accept the older bills.

The more common national currencies such as the South African rand can be purchased at the local bank prior to leaving home. Advance notice is required for some of the more unusual currencies, and still other currencies are not available at all. Currency exchange will require a local address for the paperwork.

It is advisable to take a few smaller-denomination bills for taxi rides to and from the home airport. Having to pay for an inexpensive taxi ride with a large bill for which the driver has no small change will cause consternation. Some countries require airport taxes when departing. The more common national currencies such as American dollars are often accepted for these departure taxes, but generally no monetary change is available.

\section{Credit cards}

It is essential that bank and credit-card companies be notified in advance of the exact dates and places of travel. Card companies often refuse to honor a card being used in an unusual location. One of the authors experienced denial of a card even after notification was given twice prior to leaving home; the telephone number of the card company and a distressed international call helped correct that difficult situation. Credit cards are accepted in most major cities, but almost never in remote villages. When relying on a credit card, be sure to withdraw sufficient local currency while in the airport city to meet needs for the length of time spent in rural areas. Remember that each time a withdrawal or purchase is made using a credit/debit/ATM card, there is an international charge; these accumulate rapidly.

\section{ATM cards}

These have become prevalent in some of the most remote locations. However, if there is an electricity outage with the ATM card inside the machine, a long delay may occur while waiting for the electricity to return and the card to be released. This is not an imagined scenario; fortunately for us, only an anxious 10-minute wait was required until the card was returned.

Reserve sufficient local money to purchase lunch at the airport when leaving, but try to spend most local currency. Use up any change, since coins are never accepted in banks when trying to exchange currencies. Be very honest about how much local money is leaving the country with you; some countries are sensitive about this and may appropriate what is considered excess cash. 


\section{Personal hygiene}

One regular-size roll of toilet paper will be enough to see the traveler through the first day in-country. Local rolls will consist of smaller, more abrasive paper in most cases, and will be costly. A small packet of wet-wipes will substitute for bathing during lengthy overland travel. Women should consider packing tampons, since such amenities are seldom available in rural locations.

Just a comb and a bar of soap for hair care will suffice during short-term visits. However, a little more luxury can be available; one hotel-size shampoo bottle provides everyother-day hair-washing for a week. Lightweight blow-dryers that switch from $120 \mathrm{~V}$ to $240 \mathrm{~V}$ are available.

Hand sanitizers in small bottles to fit in cargo-pant pockets will substitute for a lack of soap and running water, or even disposable gloves in some clinic sites. When patients present with communicable/infectious diseases, frequent hand-sanitizing is a good thing for both the care provider and the next patient in the queue.

One toothbrush and one small toothpaste tube per week of the trip should suffice. Nail clippers can serve both for personal hygiene and as a tool for small tasks. One of us had to use a nail file to repair a hotel door so that it would close securely. A pair of good tweezers will assist in removing splinters, a common problem in developing countries, and can also be part of a hygiene kit.

\section{Clothing}

Laundry service is typically available while traveling. Clean clothing is usually returned in 2-3 days, pressed, folded, and ready to wear. This turnaround time requires four articles of each type of clothing in order to assure clean apparel each day. Individuals who elect to do their own laundry should take a small box of laundry detergent in its original packing. A few clothespins to hang wet clothing will be appreciated. Most lodges do not have clothes hangers, but these take up significant luggage space. The authors recommend that travelers resign themselves to folded clothing stored on shelves.

Women should take a T-shirt, a modest-length skirt or pants (defer to local customs), an underwear set, and a pair of socks for each of 4 days. Men will select their appropriate equivalents. Athletic bras stand up to local laundering better than delicate underwear. Disposable panties and briefs can be purchased through catalogs or online, and last for about three washings. Two pairs of cargo pants, a much better choice than jeans, will suffice for short-term trips. Cargo pants provide pockets with snaps so that legal papers and currency can be carried about without attracting attention; vests with pockets provide the same convenience. Busy clinicians do not have time to keep track of purses, wallets, or to fend off pickpockets. Take lightweight cottons that breathe and do not require ironing. Additional clothing recommendations include two sets of pajamas, a rain poncho, a scarf (in case women are required to cover their heads), and a lightweight fleece jacket that can serve as pillow, robe, blanket, and warm outer clothing as needed.

Many of these recommendations are for tropical or subtropical destinations. However, the essential supplies do not vary greatly based on destination. The three of us sometimes work in the southern tropics in summer, but return home through a wintry Northern Hemisphere city. The fleece jacket plus layers of T-shirts provide warmth. A couple of pairs of heavy tights to wear under cargo pants, thick socks, and a pair of warm gloves will provide additional warmth. The head scarf can serve as a neck warmer.

The authors recommend a minimum of two pairs of broken-in shoes: one breathable pair with slightly more coverage than sandals, and a second pair of inexpensive thong shoes for comfort when around the "home" at night. The second pair provides protection from fungal infections in communal showers, and from snakes and poisonous insects that object to being trod upon in the dark. A good pair of walking shoes, although heavy, may be useful as well. The inside of each shoe provides space for packing small items; socks and underwear are good candidates.

\section{Miscellaneous}

In case the worst happens, an emergency-airlift policy will allow an individual to be picked up from an in-country hospital and jetted home to a receiving hospital. The card identifying this policy should be attached to the outside of one's purse or luggage.

Luggage tags during the flight to the low-resource country should have the address of the site to which one is traveling rather than the home-country address. It is not helpful for lost luggage to be returned to one's home when it is needed in the destination country. When leaving, change the tags to the home-destination address.

Electrical considerations include: (1) plug adapters for electronic equipment; warning: adapters only allow an electrical device to be plugged in, and do not alter the voltage; many countries have much higher voltages than personal equipment can handle; (2) a small transformer and 
electricical outlet plugs suited for the destination country; and (3) an extra fuse for the adapter, available at any Radio Shack. A helpful chart can be found at the Global Electric and Phone Directory website. ${ }^{15}$

Most cell phones will work in other countries, but check before leaving home. Cell-phone companies can often add international calling features for a fee. Consider the purchase of a local, in-country phone, since the rates are usually much lower.

A small roll of duct tape will be useful for many things, such as repairing shoes with torn-away soles, or luggage fasteners that break mid-trip.

\section{Nice-to-have items}

This section covers items we have been very happy to have, such as extra earpieces for a stethoscope, but without which survival was possible. It is categorized into personal safety, medicine, personal hygiene, and entertainment.

\section{Personal safety}

We have had wonderful experiences trusting local people. Home visits with local friends can result in amazing hospitality. However, one should use caution in today's world. Let someone in the party know the details of the excursion and the time of return. No one should go out alone. A cell phone and a copy of the name, phone number, and address of the lodge or guesthouse where one is staying are additional safety precautions.

One of us was not met at midnight as expected upon arrival in the target-country airport. The country's alphabet was an elaborately beautiful, non-Western script, so she could not even write a note for a taxi driver to read. Fortunately, she had the business card of her contact written in the local language, and the taxi driver knew the destination from the card.

\section{Medicine}

A tube of concentrated glucose can be obtained over the counter at any pharmacy in case a member of the party should have a hypoglycemia episode.

\section{Personal hygiene}

Facial tissues, small-purse size, at one pack per each week of the trip will be sufficient for people who are healthy. In case of rhinitis, the local, scratchy toilet paper is a fair substitute. There are seldom facecloths available for bathing, so consider a bath net ball. This can be rinsed out after each bath, and dries quickly even in the humid tropics. Bath towels can be purchased locally, but a small microfiber hand towel will serve the same purpose and take up little luggage space. Hotel-size deodorants and lip balm will complete the hygiene list.

An extra backpack that can be placed empty inside the larger luggage will serve if overnight forays into distant places from the home base are required, and will provide extra baggage for souvenirs. Local maps are available in most capital cities, but are not always as detailed as needed. A guidebook will provide local destination suggestions for vacation days should this luxury be available.

If the flight is lengthy, earplugs and an eye mask will aid in sleep on the plane. These are particularly helpful in airport waiting areas during prolonged layovers. We have been stationed in areas with roosters and dogs nearby; the earplugs were extremely welcome additions.

A modest swimsuit, shower cap, and gifts for host families complete the nice-to-have list. Ideally, gifts should be lightweight for packing and be unique to your own home country. Ideas include T-shirts from local universities or key chains representing cities.

It is best to leave anything valuable at home. Jewelry, expensive cameras, and video equipment draw unwanted attention. There are always concerns about theft, so individuals must decide how much risk they are willing to take. Do not count on lodges having secure locks or safes. Luggage locks, while helpful en route, only mean the thief will have to carry away the entire suitcase rather than be selective about its contents.

At the end of trips in very impoverished countries, it is nice to leave clothing and shoes you no longer need for the guesthouse maids.

\section{Entertainment}

A recent trip to Zambia found two of us in a location with one television channel that showed football 24-7. For those who are not sports fans, paperback books help to pass the time and can be left for in-country friends, expatriates, and in guesthouses. A book of sudoku or crossword puzzles provides variety. A more modern but less friendly approach is the electronic book. The e-book is much lighter, saves luggage space, but is more tempting to thieves. Some electronic devices will allow movie rental or purchase.

\section{Conclusion}

These recommendations have served the three of us well on many trips to various locations. Some world travelers will disagree with these lists. Some will want more, and we wish them well as they struggle to carry the weight of the luggage. 
Some will be able to thrive with much less; for those hearty souls, we have the greatest respect. Having the right supplies on hand for each individual's personal needs goes a long way toward enhancing the pleasure obtained from helping improve health care around the world. The nursing profession is known for being prepared; we hope the information in this article facilitates that characteristic.

\section{Disclosure}

The authors report no conflicts of interest in this work.

\section{References}

1. Saenz K, Holcomb L. Essential tools for a successful study abroad course. J Nurs Educ. 2008;34(4):172-175.

2. MedicalMissions.org. http://www.medicalmissions.org. Accessed September 3, 2012.

3. Nursing.org. Mission trips. Available from: http://www.nursing.org/ default.pk?tsearch=missions. Accessed September 3, 2012.

4. US Department of State Bureau of Consular Affairs. Country specific information. 2012. Available from: http://travel.state.gov/travel/ cis_pa_tw/cis/cis_4965.html. Accessed June 5, 2012.

5. Patrono C, Baigent C, Hirsh J, Roth G. American College of Chest Physicians. American College of Chest Physicians Evidence-Based Clinical Practice Guidelines. 8th ed. Chest. 2008;133(Suppl 6):199S-233S.

6. Clarke MJ, Hopewell S, Juszczak E, Eisinga A, Kjeldstram M. Compression stockings for preventing deep vein thrombosis in airline passengers. Cochrane Database Syst Rev. 2006;2:CD004002.
7. Centers for Disease Control and Prevention. Travelers' diarrhea. 2006. Available from: http://www.cdc.gov/ncidod/dbmd/diseaseinfo/ travelersdiarrhea_g.htm. Accessed May 6, 2012.

8. Kennedy B. Nurse Practitioner's Prescribing Reference. New York: Haymarket Media; 2011.

9. Department of Child and Adolescent Health and Development (CAH). Oral Rehydration Salts: Production of the New ORS. Geneva: World Health Organization; 2006. Available from: http://whqlibdoc.who.int/ hq/2006/WHO_FCH_CAH_06.1.pdf. Accessed June 5, 2012.

10. Dey Pharma. About EpiPen (epinephrine) auto-injector. 2011. Available from: http://www.epipen.com/about-epipen/overview. Accessed June 5, 2012.

11. Centers for Disease Control and Prevention. Destinations. 2012. Available from: http://wwwnc.cdc.gov/travel/destinations/list.htm. Accessed June 5, 2012.

12. World Health Organization. International travel and health: rabies. 2012. Available from: http://www.who.int/ith/vaccines/rabies/en. Accessed May 6, 2012.

13. Centers for Disease Control and Prevention. Choosing a drug to prevent malaria. 2011. Available from: http://www.cdc.gov/malaria/travelers/ drugs.html. Accessed May 6, 2012.

14. Kelley D. How to get an international drivers permit or license. Available from: http://businesstravel.about.com/od/internationaltravel/ ht/Getting-an-international-drivers-permit-or-license.htm. Accessed June 5, 2012.

15. Global Electric and Phone Directory. Electric power around the world. Available from: http://www.kropla.com/electric2.htm. Accessed May 6, 2012.
Nursing: Research and Reviews

\section{Publish your work in this journal}

Nursing: Research and Reviews is an international, peer-reviewed, open access journal publishing original research, reports, reviews and commentaries on all aspects of nursing and patient care. These include patient education and counselling, ethics, management and organizational issues, diagnostics and prescribing, economics and

\section{Dovepress}

resource management, health outcomes, and improving patient safety in all settings. The manuscript management system is completely online and includes a very quick and fair peer-review system. Visit http://www.dovepress.com/testimonials.php to read real quotes from published authors. 